\title{
Memoria: Revisión conceptual
}

\author{
Memory: a conceptual review
}

\section{Fátima Alaniz-Gómez ${ }^{a}, F_{\text {Fernanda Belén Durán-Pérez }}{ }^{b}$,Brenda Lizeth Quijano-Ortiz ${ }^{c}$, Tamara Salas- Vera $^{d}$, Jesús Cisneros-Herrera ${ }^{e}$ y Gelacio Guzmán-Díaz ${ }^{f}$}

\begin{abstract}
:
Memory is a psychological process that stores, codes and retrieves concepts, events, facts, etc., which can be used in several areas of daily life. This review, presents not exhaustively a set of antecedents and definitions of memory. Moreover, some classifications and models of memory found in the literature are reviewed. Finally, some strategies for boosting memory and its assessment are presented.

Keywords:

Memory, types of memory, boosting of memory

\section{Resumen:}

La memoria es un proceso psicológico que almacena, codifica y recupera conceptos, acontecimientos, hechos, etc. que son aplicables en momentos y áreas de la vida diaria. La presente revisión, sin ser exhaustiva, presenta una serie de antecedentes y definiciones de la memoria. Así mismo se revisan algunas clasificaciones y modelos de la memoria encontradas en la literatura. Finalmente se presentan algunas estrategias para la estimulación de la memoria y su evaluación.
\end{abstract}

\section{Palabras Clave:}

Memoria, Tipos de memoria, Estimulación de la memoria.

\section{Memoria Antecedentes}

Al hablar de memoria es necesario conocer el término, el cual proviene del latín memini que significa grabar o incrustar. Dicha raíz hace alusión a la existencia de una huella de información que fue procesada previamente la cual es posible regresar mediante la recolección o el recuerdo. Sin embargo, la memoria no es un órgano que se pueda ver, radiografiar o tocar ${ }^{1}$.

El momento histórico dentro del cual la memoria comienza a cobrar auge es a finales del siglo XIX, con William James, primer filósofo y psicólogo norteamericano que propone el modelo dual de la memoria conformado por la memoria primaria o inmediata, que hace alusión a una corta duración y almacena información consciente en un momento determinado; y por la memoria secundaria, de larga duración que contiene la variedad de conocimientos adquiridos durante toda la vida1, 2,3

Asimismo, de acuerdo con Ballesteros (1999, 2012) ${ }^{4,1}$, Tortosa y Civera $(2006)^{5}$ y Pelegrina, Lechuga, Castellanos y Elosúa $(2016)^{3}$ el interés por el estudio científico de la memoria al mismo tiempo comenzó a finales del siglo XIX en Alemania con el psicólogo Hermann Ebbinghaus quien realiza la primera investigación basada en el método científico-experimental de la memoria llevándolo al laboratorio con estudios en condiciones controladas.

Dicho estudio consistió en saber cómo se retienen las silabas sin sentido o trigramas. Todo ello empleando el "método de los ahorros", el cual consistía en calcular el

Autor de Correspondencia, Universidad Autónoma del Estado de Hidalgo, https://orcid.org/0000-0001-6617-0625, Email: al341134@uaeh.edu.mx

b Universidad Autónoma del Estado de Hidalgo, https://orcid.org/0000-0002-6348-4503, Email: du419152@uaeh.edu.mx

c Universidad Autónoma del Estado de Hidalgo, https://orcid.org/0000-0002-7363-2207, Email: qu338332@uaeh.edu.mx

d Universidad Autónoma del Estado de Hidalgo, https://orcid.org/0000-0002-5005-9479, Email: sa419236@uaeh.edu.mx

e Universidad Autónoma del Estado de Hidalgo, https://orcid.org/0000-0003-1370-8086, Email: jesus_cisneros@uaeh.edu.mx

${ }^{\mathrm{f}}$ Universidad Autónoma del Estado de Hidalgo, https://orcid.org/0000-0003-4869-8658, Email: gelacio_guzman@uaeh.edu.mx 
tiempo necesario para realizar un aprendizaje inicial de la serie de trigramas.

Ante dicha investigación "Sobre la memoria", Ebbinghaus propone un modelo teórico basado en los supuestos:

- Las representaciones de la memoria tienen forma de imágenes.

- Cuando dos elementos ocurren simultáneamente se asocian en la memoria.

- Las propiedades de la memoria pueden llegar a descubrirse al estudiar sus unidades simples.

Dicho modelo planteaba que se da una representación del material, creándose conexiones, así cuando el estímuloobjetivo se recupera, se hace consciente y se trae de la memoria. Sin embargo el modelo ha planteado terreno ante los nuevos modelos asociativos modernos que el estímulo-objetivo se encuentra en la memoria a largo plazo $^{4,5,3}$.

Otro investigador que plantea un antecedente y también considerado un pionero en el estudio de la memoria fue el psicólogo inglés Frederick Barlett en la primera mitad del siglo XX, quien, a diferencia de Ebbinghaus, leía narraciones a los participantes de la investigación, solicitándoles que recordarán después la lectura. Su interés principal era averiguar qué tipo de organización seguía el material registrado en la memoria de los participantes, destacando los esquemas de la memoria y el recuerdo posterior. Utilizó el método de la reproducción repetida, de esta forma él estudiaba la transformación en la reproducción de las historias contadas ${ }^{2}$.

En cuanto a los avances en la investigación experimental de la memoria, estos surgieron a la mitad del siglo $X X$, época en que George Ellias Miller realizó importantes innovaciones y mejoras en el instrumental de investigación y métodos, así como propuso el término "memoria inmediata" y junto con diversas pruebas que cuantificaban su limitada capacidad, sugirió que dicha limitación influía en la ejecución de una amplia variedad de tareas mentales ${ }^{5,3}$.

Concluyendo con la década de los años sesenta, en donde comenzaron a acumularse evidencias que diferenciaban la memoria a corto plazo de la memoria a largo plazo; así como estudios sobre el recuerdo libre y los efectos de primacía y efectos de cercanía que ocurría en una lista de ítems a recordar ${ }^{3}$.

Abeleira $(2013)^{6}$ subraya que la memoria es un desarrollo psicológico que almacena, codifica y recupera acontecimientos, conceptos y procedimientos que aplicamos en las diferentes áreas y demandas de la vida diaria. También es un proceso mental, el cual debe cuidarse y ejercitarse para poder sobrevivir y convivir con nuestro entorno. Al ser parte de nuestro organismo sufre desgaste con el paso de los años y ciertas pérdidas son inevitables.
Igualmente, Varela, Ávila y Fortoul citado por Félix, Amor, Leal y Castro $(2017)^{7}$ apunta que la memoria es un proceso, el cual permite registrar, codificar, consolidar y almacenar la información.

Por otro lado, Gazzaniga, Ivry, y Mangun (2014) $)^{8}$ focalizan que al hablar de memoria es necesario hablar del proceso de aprendizaje, entendido como una continua adquisición de información y conocimiento que va hacia la memoria. En este sentido la memoria involucra el retener información, experiencias, o acciones lo cual puede durar segundos, minutos, horas o toda la vida.

Para Ballesteros $(1999,2012)^{4,2}$ describe la memoria como el proceso psicológico útil para codificar, almacenar y recuperar información de forma voluntaria o involuntaria, cuando le es necesario al individuo. Siendo su principal valor el ser adquirida a través del aprendizaje, la rapidez y la precisión. Así como los elementos importantes a considerarse son el lenguaje, los conocimientos anteriormente adquiridos y la historia personal.

Por lo que concuerda con las 3 etapas que proponen Gazzaniga, Ivry, y Mangun (2014) ${ }^{8}$ :

1. Codificación: A la vez se divide en 2 etapas: adquisición, cuando el sistema sensorial es bombardeado por estímulos; y consolidación, donde la información se estabiliza, dando como resultado la memoria a largo plazo.

2. Almacenamiento: Es la retención y permanencia de datos en la memoria.

3. Recuperación: Es el acceder a la información previamente almacenada en la memoria. Puede ser consciente o como un acto motor.

\section{Modelos de memoria}

Donald Broadbent citado por Ballesteros $(2012)^{2}$ propone el modelo del filtro o de selección temprana, donde las características físicas de un mensaje auditivo focaliza al atención, filtrando los mensajes irrelevantes. Esto planteándose desde la perspectiva que la capacidad de la memoria es limitada y el ser humano únicamente es capaz de atender un número limitado de estímulos en un momento determinado.

Por su parte, Atkinson y Shiffrin (1968) citados por Ballesteros $(1999,2012)^{4,2}$ y Pelegrina et al. $(2016)^{3}$ Proponen el modelo multialmacén, el cual refiere que la memoria está formada por distintas estructuras principales, que dirigen el flujo de información a través de los diferentes almacenes fijos de memoria. Ante ello, la memoria tiene tres almacenes: registros sensoriales, memoria a corto plazo (MCP) y memoria a largo plazo (MLP).

El almacén de los registros sensoriales, están conformados por el registro visual y auditivo, es decir, el 
momento de registro ocurre al mismo tiempo que la información del medio ambiente llega a los registros. Pasando la información al almacén de la memoria a corto plazo, el cual tiene una capacidad limitada, lo contenido decae más lentamente que en los registros sensoriales. Este almacén elige la repetición y codificación de la información así como qué información se transferirá a la memoria a largo plazo, siendo este último el que posee un almacenamiento permanente (Ballesteros, 2012)2.

Por último, Squire citado por Ballesteros $(2012)^{2}$ propone la división de la memoria a largo plazo en memoria declarativa y memoria procedimental, de acuerdo al tipo de información a recordar. Ya que la memoria declarativa son aquellas proposiciones o imágenes que forman parte de hechos. La memoria procedimental, por su parte, no depende de la repetición ni distracción, está relacionada con el saber de las cosas, registra información de un modo casi permanente.

\section{Tipos de memoria}

Los modelos o tipos de memoria según Gazzaniga et al. $(2014)^{8}$ son: Memoria sensorial, Memoria a corto plazo, Memoria de trabajo, y Memoria a largo plazo. Mientras que Tulving citado por Sejias $(2015)^{9}$, establece una división de la memoria, basándose en el contenido almacenado y las características propias, dando lugar a la memoria semántica y a la memoria episódica. Otra división distingue entre memoria declarativa o explicativa y memoria no declarativa o implícita. Teniendo un subtipo en la memoria explícita, la memoria episódica y semántica. A continuación se describe cada uno de estos tipos.

La memoria sensorial es aquella que persiste por milisegundos, segundos o minutos dependiendo del estímulo recibido que involucre los órganos sensoriales. Por ejemplo, la memoria ecoica es la que proviene de la escucha y la memoria icónica la que proviene de la visión ${ }^{8}$. Lo cual indica que la memoria sensorial es aquella que se relaciona con la llegada de la información a un órgano receptor, hasta que el cerebro llega a percibir dicha información ${ }^{10}$.

La memoria sensorial es aquella que recibe los inputs, es decir los eventos externos, siendo esta el primer momento de registro, el almacenaje será breve, siendo únicamente una impresión inicial del evento o ambiente externo (Klein, 1994 citado en Jaúregui y Razumiejczyk, 2011) ${ }^{11}$. Dentro de este tipo de memoria, la información decae con rapidez, por lo que generalmente no llega a ser procesada en la memoria a corto plazo o en dado caso continua su proceso en el sistema cognitivo. ${ }^{11,2}$

\section{Memoria a corto plazo.}

La memoria a corto plazo desde el punto de vista de Padilla y Bajo $(1998)^{12}$ implica procesos de repetición, recodificación, etc. Mientras que Lopera $(2008)^{13}$, establece que la función de la memoria a corto plazo es convertir aquella información adquirida en huellas de memoria a largo plazo. Acorde a Kandel citado por Orrego y Tamayo $(2016)^{14}$ dentro de este tipo de memoria es importante la repetición de la experiencia, para que de esta forma se genere el cambio de memoria a corto plazo hacia la memoria a largo plazo.

En general y de forma simple, Ballesteros $(2012)^{2}$ define la Memoria a Corto Plazo como un almacén con una limitada duración (usualmente de 10 a 20 segundos) y una limitada capacidad de almacenamiento por lo que suele estar entre los 5 y 9 elementos independientes. Asimismo tiene funciones de control importantes, ya que se encarga de tomar la decisión si la información va a ser transferida a la MLP y que estrategia de control utilizará. Es capaz de retener la información por tiempo breve, el cual usualmente dura segundos, hasta que llega a la Memoria a largo plazo (MLP).

Richar Atkinson y Richars Shiffrin en Gazzaniga et al. $(2014)^{8}$ plantean un modelo donde se establece que la información como primera instancia se almacena en la memoria sensorial, de ahí hay ciertas partes seleccionadas que se guían hacia el proceso atencional, teniendo por última instancia la memoria a corto plazo, donde ya puede ser guiada a la memoria a largo plazo. Dicho modelo de igual manera propone que en cada etapa la información puede degradarse, ser interferida, o ambas.

\section{Memoria de trabajo o memoria operativa.}

Padilla y Bajo (1998) ${ }^{12}$ establecen que la memoria operativa ejecuta la función de ir encadenando la información nueva que recibe de forma verbal con información anteriormente adquirida por la experiencia, los conocimientos de la memoria a largo plazo, etc. Siendo la memoria operativa un mecanismo de almacenamiento y procesamiento de información, que posee la capacidad de reactivación de información pasada almacenada en la memoria a largo plazo, por lo que es pasiva.

Para Gazzaniga et al. $(2014)^{8}$ la memoria de trabajo es un tipo de memoria a corto plazo, en donde remite el mantenimiento temporal de la información y la capacidad de manipular dicho contenido. La memoria de trabajo, acorde a Tirapu y Muñoz (2005) ${ }^{15}$ es la capacidad de mantener la información en línea, así como mantener los recursos atencionales en orientación y adecuación necesaria, inhibir las respuestas inapropiadas ante ciertas circunstancias y monitorizar la conducta conforme a la emoción y motivación del sujeto. 
Lopera $(2008)^{13}$ define la memoria de trabajo como aquella memoria que registra y almacena la información adquirida para futuras metas, es decir, un proceso constante de activación de memorias que ya estaban previamente registradas y que se van actualizando con los contenidos presentes en la cognición. Asimismo Manes y Torralba $(2005)^{16}$ definen la memoria de trabajo como la información que el sujeto es capaz de mantener en el momento y que llegará a ocupar en corto tiempo, mientras realiza alguna tarea.

De acuerdo con Baddeley (2012) $)^{17}$ la diferencia entre memoria de trabajo y memoria a corto plazo reside en que la memoria a corto plazo es un periodo corto de tiempo donde se almacenará la información, mientras que la memoria de trabajo implica la combinación de almacenamiento y manipulación.

Para Baddeley citado por Padilla y Bajo $(1998)^{12}$, la memoria operativa es considerada como la retención y procesamiento de información, que a su vez contribuirá en el razonamiento y comprensión de la persona.

\section{Memoria a largo plazo.}

La memoria a largo plazo de acuerdo con Padilla y Bajo $(1998)^{12}$, involucra una adición simultánea de conocimientos extraídos de la recepción del mensaje. Fuenmayor y Villasmil $(2008)^{10}$ establecen que la memoria a largo plazo está constituida por todas las experiencias, conocimientos y saberes que se almacenan a lo largo de la vida, por lo que crece su relevancia. De igual forma, toma en cuenta que tiene una capacidad infinita de almacenar información, además de realizar el proceso de adquisición y organización, dando pie a la lectura y comprensión.

Endel Tulving citado por Gazzaniga et al. $(2014)^{8}$ y Ballesteros $(2012)^{2}$ divide la memoria a largo plazo en dos: la episódica y la semántica. Donde, la memoria episódica habla de memorias personales, que contienen experiencias de hechos pasados, por ello es que funciona a nivel consciente y su recuperación es voluntaria y explícita, en la que se recuerda el lugar en donde ocurrió y el aspecto, así como involucra la percepción; mientras que la memoria semántica es aquella encargada de poseer la cantidad de palabras que conforman el vocabulario del sujeto, el conocimiento general que posee acerca de todo lo visto, oído, etc. propagado a través de redes semánticas. Recuerda los hechos sin contexto, es decir, desconoce dónde o cuándo fueron aprendidos.

Acorde a Ballesteros (2012) $)^{2}$ y Gazzaniga et al. $(2014)^{8}$ se debe realizar la distinción entre la memoria declarativa y no declarativa. La memoria declarativa o explicita puede ser definida por ser la memoria de eventos y hechos tanto generales como personales, así como ser accesible de manera consciente y de forma verbal, es decir, implica recuerdos conscientes sobre objetos, lugares, acontecimientos y personas.

La memoria no declarativa o implícita, es aquella a la que la conciencia no tiene acceso, comprende hábitos, destrezas perceptivas y motoras, teniendo este tipo de memoria sus subtipos, la memoria procedimental o también llamada memoria de habilidad que depende de la repetitividad de la experiencia, donde los movimientos 0 las acciones que involucren cognición ya no se realizan de manera consciente sino en forma de procedimiento habitual; y el primado, que es otra forma de memoria no declarativa, el cual se refiere a la identificación de estímulos, o algún cambio de respuesta a este, que puede ser perceptual, conceptual o semántico.8,2

\section{Modelos de memoria de trabajo}

El modelo multialmacén de la memoria propone la Memoria a Corto Plazo como una memoria activa cuya función es retener una pequeña cantidad de información por un periodo corto de tiempo la cual sirve para realizar diversas funciones cognitivas como lo son el aprendizaje, la repetición, tareas de razonamiento comprensión del lenguaje ${ }^{2}$. Sin embargo Baddeley y Hitch citados por Ballesteros $(2012)^{2}$ dan paso a preguntar ¿para qué sirve la MCP?, siendo su razonamiento que si la MCP se dedica a 2 tareas, ambas exigiendo y dependiendo de la MCP, la realización de la segunda tarea será mala.

Por lo que realizaron una investigación en donde los sujetos debían recordar series de 1 a 8 dígitos a la vez que realizaban alguna tarea de razonamiento sintáctico (jerarquías) que aumentan en la dificultad. En este caso la tarea era colocar en orden la secuencia de dígitos y comprobar si las frases a comprobar eran verdaderas o falsas, todo conforme a la rapidez de respuesta y el número de errores en el número de dígitos ${ }^{2 .}$.

Baddeley y Hitch citados por Ballesteros (1999) ${ }^{4}$, Tirapu y Muñoz (2005) ${ }^{15}$ y Pelegrina, et al. $(2016)^{3}$ llegaron a la conclusión que el procesamiento y almacenamiento comparten algunos recursos pero a la vez son independientes y cada uno tiene estructuras y mecanismos distintos. Llevándolos a plantear distintas estrategias para diferenciar las funciones de mantenimiento de las funciones de manipulación durante la realización de varias tareas, siendo este el origen del modelo de memoria a corto plazo que nombraron memoria de trabajo.

Acorde con Ballesteros (2012) $)^{2}$ en el modelo original proponen que la memoria de trabajo está conformada por diversos sistemas organizados de forma jerárquica entre sí y coordinados. Siendo sus componentes: el ejecutivo central, el bucle fonológico o articulatorio y la agenda visoespacial. Aunque, tenía un principal problema, explicar cómo se relacionaba la MT con la MLP, es por ello que 
Baddeley (2000) citado por Ballesteros $(2012)^{2}$ propuso un modelo actualizado, llamándolo Modelo multicomponente de la Memoria de trabajo, presentando adiciones:

La MLP es conectada desde los subsistemas fonológico y visoespacial. Así como un almacén o retén episódico cuyo acceso podía ser desde el ejecutivo central, el sistema visoespacial y el bucle fonológico. ${ }^{2,3}$

Bucle fonológico o articulatorio o lazo articulatorio:

Encargado de conservar transitoriamente la información auditiva, por lo que de igual forma repasa continuamente la información verbal para permitir el mantenimiento temporal a lo largo de la realización del trabajo cognitivo. Está conformado por el sistema de control articulatorio cuya función es la actualización de los estímulos mediante la repetición subvocal, dichos estímulos se encuentran en el otro elemento que compone al bucle articulario, el almacén fonológico, el cual es un sistema de almacenamiento de información verbal durante menos de 5 segundos. 2,3

Prueba de que la información se mantiene en el bucle es el efecto de interferencia por similitud fonológica. En tareas de acuerdo a un recuerdo inmediato, hay más errores en el recuerdo de listas a medida que las palabras que comparten más características fonológicas, este incremento de errores no se dan en palabras con características semánticas parecidas. Es decir, el efecto de longitud de la palabra, que se da en tareas de recuerdo inmediato, consiste en que las palabras con mayor número de silabas se recuerdan menos que las que se pronuncian rápidamente, interpretándose como evidencia que el bucle fonológico hace uso del sistema de articulación vocal y la capacidad de mantenimiento se define en términos de duración de la pronunciación del contenido. $^{3}$

Otro efecto es el de la supresión articulatoria, el cual consta de ser un procedimiento experimental donde se pronuncia contenido irrelevante durante la presentación y recordación de una lista de palabras. Generando una disminución en el recuerdo, eliminando el efecto de la longitud de la palabra, haciendo que el recuerdo de listas con palabras largas sea bajo pero no elimina completamente la capacidad de mantener activa la información verbal adquirida. ${ }^{3}$

La agenda viso-espacial:

Es el subsistema utilizado para manipular y conservar información de lo visual y espacial que rodea al sujeto, así como el procesamiento de dichas imágenes. Siendo posible distinguir entre los aspectos espaciales (localización). Dicha agenda está limitada en la cantidad de imágenes independientes que es capaz de manipular simultáneamente. Por lo que ante el recuerdo inmediato de localizaciones existe poco olvido por periodos breves de tiempo exceptuando cuando se ve implicada alguna tarea distractora durante el mantenimiento. ${ }^{2,3}$
El ejecutivo central:

Llega a considerarse el componente más importante del sistema, es quien se encarga de controlar y gestionar, responsable de focalizar la atención y controlar de esta manera la conducta. Por lo que Baddeley (1996) citado en Pelegrina et al. (2016) $)^{3}$ adopta la propuesta de Norman y Shallice (1986) citada en Pelegrina et al. $(2016)^{3}$ planteando que el ejecutivo central mantiene dos modos de control:

1. Automático: Para destrezas existentes, hábitos.

2. Controlado: responsable de la realización de tareas complejas.

Además, el ejecutivo central realiza cuatro funciones ejecutivas:

- Dirige la atención hacia la realización de una tarea en curso

- Divide la atención y coordina la relación entre dos o más tareas simultaneas

- Cambia flexiblemente el foco atencional entre tareas

- Activa y recupera la información de la memoria a largo plazo. ${ }^{2,3}$

El retén o almacén episódico:

Este cuarto componente propuesto por Baddeley citado en Pelegrina et al. (2016) $)^{3}$ es planteado para explicar la relación entre la memoria de trabajo y la memoria a largo plazo. Este sistema de almacenamiento temporal mantiene un enlace entre los distintos subsistemas, conectándolos con la memoria a largo plazo permitiendo la combinación de información.

\section{Modelo de almacenamiento unitario.}

Por otra parte, Nelson Cowan citado por Pelegrina et al. $(2016)^{3}$ propone un modelo de almacenamiento unitario, difiriendo de la propuesta multialmacén de Baddeley. EI modelo de procesos integrados de la memoria de trabajo de Cowan citado por Pelegrina et al. $(2016)^{3}$ asume la existencia de disociaciones entre procesos verbales y visoespaciales.

El modelo de los procesos integrados contempla dos componentes que integran la activación alcanzada por la información en la memoria:

1. Las representaciones se activan por la entrada de la información al sistema. Conformadas principalmente por naturaleza sensorial, aun cuando hay cierto nivel de activación no llega a ser accesible a la consciencia.

2. Capacidad limitada. Hay una constante degradación en las representaciones como resultado de las interferencias y el decaimiento de la activación.

De igual forma, se añade el componente del "foco de atención" el cual es un subconjunto de la memoria a largo plazo. Una vez que la información ingresa al foco de atención es accesible a la consciencia, por lo que depende 
de procesos voluntarios (aquellos controlados por el sistema ejecutivo central) e involuntarios y automáticos (sistema de orientación atencional). La función más importante del foco de atención es el lograr el establecimiento de vínculos episódicos entre elementos activados, permitiendo al sujeto recordar y asociar ítems realizando nuevas combinaciones que podrán mantenerse de forma permanente. La capacidad del foco de atención se encuentra limitada en el ritmo en al que puede activarse la información, es decir, la cantidad de los distintos elementos (chunks) que puede llegar a contener. Dicha capacidad puede ser comprobada ante la imposición de sobrecarga de información en un corto tiempo (Cowan, 1988, 1995, 2005 citado por Pelegrina et al., 2016) $)^{3}$.

\section{Modelo concéntrico de memoria de trabajo.}

De igual importancia, Obrauer citado en Pelegrina et al. $(2016)^{3}$ sugiere el modelo concéntrico de memoria de trabajo que es conformada por tres niveles:

1er nivel. Región activada de la memoria a largo plazo, donde las representaciones se encuentran activadas por encima de la activación de otras representaciones.

2do nivel. Región del acceso directo, el cual coincide con el foco de atención propuesto por Corwan. Donde un número de representaciones activas están relacionas al contexto y son accesibles.

3er nivel. Foco de atención, que debe tener un sólo elemento mantenido en la región de acceso directo, estando en un estado de disponibilidad inmediata.

\section{Memoria y su estrategia de estimulación}

Acorde con Rundus (1971) citado en Ballesteros (2012)2 la repetición de la información prolonga su duración en la memoria, es decir cuando más largo sea el tiempo sea la presentación y repetición mejor será su codificación en la Memoria a Largo Plazo.

Baddeley (1990) citado por Ballesteros $(2012)^{2}$ sugiere el aprendizaje semántico, es decir el realizado a un nivel profundo, produciendo mayor aprendizaje y mejor recuerdo de la información. Asimismo indica que la repetición activa la información a retener, hay un mantenimiento activo durante cierto tiempo, haciendo posible la integración de dicha información con otros materiales existentes.

\section{Estrategias de estimulación de la memoria de trabajo.}

La memoria operativa está compuesta por un ejecutivo central de capacidad limitada, la cual organizaría el flujo de información en el sistema el cual desempeña funciones atencionales; el bucle fonoarticulatorio que se encarga de la codificación y retención de la información verbal que influye en la adquisición de vocabulario y la agenda visoespacial. Para el entrenamiento de la memoria se debe tener en cuenta la estructura del material a recordar, es así que la información esquematizada se puede codificar con mayor facilidad, el organizar la información que esta se puede generar por categorías, el conocimiento previo del sujeto, estos influirán en aquellos esquemas que se generen, las habilidades del uso en procesos de retención y recuperación. (Etchepareborda y Abad, 2005) ${ }^{18}$.

Anteriormente se consideraba que la capacidad de la memoria de trabajo era una característica fija. Conforme los años ha sido comprobado que esta memoria puede aumentar con el entrenamiento. Habiendo aproximaciones que plantean estrategias de codificación, mantenimiento y recuperación de información en particular; el uso del repaso (repetición); la generación de imágenes mentales; la elaboración semántica en la codificación además de las estrategias que pueden llegar a relacionar son situaciones de la vida diaria en la cual la persona las emplea para retener ciertos conjuntos de información, entre otras (Pelegrina et al., 2016) ${ }^{3}$.

Para mejorar y estimular la memoria de manera preventiva se pueden utilizar estrategias mnemotécnicas que permiten recordar información personal por medio de la asociación. Como por ejemplo asociar imágenes o dibujos (Aguilar, Gutiérrez y Samudio, 2018) ${ }^{19}$.

A su vez, existen actividades que son utilizadas para la estimulación en el proceso de atención y memoria como: identificar un estímulo entre otros en el caso de la atención focalizada y sostenida. En el caso de la atención selectiva encontramos actividades que requieren del prestar atención y seguir instrucciones, por ejemplo: buscar las diferencias entre dos imágenes y encerrar en círculos todos los números 1 pequeños, luego encerrar en un círculo todos los números 2 grandes, y por último encerrar todos los números 3 sin importar su tamaño. ${ }^{20}$

Titz y Karbach citado en González et al. (2016) ${ }^{21}$ indican que investigaciones muestran que la estimulación de la memoria de trabajo, tanto en niños como en adultos, tienen resultados significativos en cuanto a las mejoras en habilidades académicas.

\section{Evaluación de la memoria}

Ballesteros $(2012)^{2}$ propone diversas formas de evaluar la memoria de larga duración:

- Recuerdo libre: Se presenta el material a retener y posterior a unos minutos, días, semanas se solicita a la persona que reproduzca dicho 
material, ya sea en el mismo orden o en el orden en que lo desee.

- Recuerdo señalado: Después de presentar el estímulo se le proporcionan al sujeto señales que ayudan a recuperar dicha información (pistas).

- Reconocimiento o "antiguo-nuevo": Se presenta al sujeto elementos mostrados anteriormente junto con nuevos, en un orden aleatorio. Su labor consistirá en establecer cuáles son los antiguos y cuáles son los nuevos.

Herdt y Pohl $(2018)^{22}$ mencionan que para evaluar la memoria de trabajo es necesario utilizar pruebas que permiten identificar los principales componentes de estas:

- En la prueba de Wechsler es posible evaluar el "bucle fonológico" de la memoria de trabajo con la retención de dígitos en orden directo, que consiste en la repetición en orden de los dígitos previamente pronunciados por el examinador. En la misma prueba, se puede evaluar el "ejecutivo central", con la retención de dígitos en orden inverso, el cual consiste en la repetición de orden inverso de los dígitos dichos por el examinador.

- Para evaluar la agenda visoespacial, podría verse involucrada el Test de copia y reproducción de memoria de figuras geométricas complejas en donde el infante debe copiar la figura en una hoja, mientras el estímulo está presente. Posterior a una pausa de 3 minutos, se le solicita que vuelva a hacer el mismo dibujo de memoria sobre otra hoja. Puntuándose la prueba en el número, posición, calidad, proporcionalidad y situación de los elementos principales y secundarios.

Por otra parte, Alsina y Sáiz (2004) ${ }^{23}$ proponen una "Batería de Test de Memoria de Treball". Involucrando pruebas de por cada elemento: bucle fonológico, agenda viso-espacial y ejecutivo central.

Papalia, Wendkos y Duskin (2009) ${ }^{23}$ propone la Escala de Inteligencia Standford-Binet, utilizada a partir de los 2 años de edad en adelante, cuenta con una duración de 45 a 60 minutos. En la prueba se pide al infante que defina palabras, ensarte cuentas, construya con bloques, identifique partes faltantes en imágenes, realice laberintos y comprenda ciertos números. La puntuación obtenida medirá el razonamiento fluido, el razonamiento cuantitativo, los conocimientos, el procesamiento visoespacial, los conocimientos y la memoria de trabajo.

\section{Referencias}

[1] Díaz, J. L. (2009). Persona, mente y memoria. Salud mental, 32(6), 513$526 . \quad$ Recuperado de: http://www.scielo.org.mx/pdf/sm/v32n6/v32n6a9.pdf

[2] Ballesteros, S. (2012). Psicología de la memoria: estructuras, procesos, sistemas. España: Universitas.
[3] Pelegrina, S., Lechuga, M.T., Castellanos, M.C. y Elosúa, M. R. (2016). Memoria de trabajo. En M.T. Bajo, L.J. Fuentes, J. Lupiañez y C. Rueda. Mente y cerebro: de la Psicología experimental a la Neurociencia cognitiva (pp. 237-262). Madrid: Alianza Editorial.

[4] Ballesteros, S. (1999). Memoria humana: investigación y teoría. Psicothema, 11(4), 705-723. Recuperado de: http://www.psicothema.com/pdf/323.pdf

[5] Tortosa, F. y Civera, C. (2006). Historia de la psicología. España: McGraw Hill.

[6] Abeleira, G. (2013). La memoria: concepto, funcionamiento y anomalías. Universidad de Salamanca, 1(5) 177-190, Recuperado de: https://dialnet.unirioja.es/servlet/articulo?codigo $=4462486$.

[7] Félix, J., Amor, I., Leal, F. \& Castro, I. (2017). Relación entre fallos de la memoria, funciones ejecutivas y estrés percibido. Universidad Complutense de Madrid España, 1(1), 1-5.

[8] Gazzaniga, M.S., Ivry, R.B. \& Mangun, G.R. (2014). Cognitive neuroscience: The biology of the mind ( $4^{\mathrm{a}}$ Ed.). Nueva York, Estados Unidos de América: W. W. Norton \& Company.

[9] Sejias Gómez, R. (2015). Atención, memoria y funciones ejecutivas en los trastornos del espectro autista: ¿cuánto hemos avanzado desde Leo Kanner? Revista de la Asociación Española de Neuropsiquiatría, 35(127), 573-586. Doi: 10.4321/S0211-57352015000300009.

[10] Fuenmayor, G. \& Villasmil, Y. (2008). La percepción, la atención y la memoria como procesos cognitivos utilizados para la comprensión textual. Revista de artes y humanidades UNICA, 9(22), 187-202.

[11] Jaúregui, M. \& Razumiejczyk (2011). Memoria y aprendizaje: Una revisión de los aportes cognitivos. Revista Virtual de la Facultad de Psicología y Psicopedagogía de la Universidad del Salvador, 26(1), 2044. Recuperado de: https://racimo.usal.edu.ar/4501/1/174-712-1PB.pdf

[12] Padilla, P. \& Bajo, T. (1998). Hacia un modelo de memoria y atención en interpretación simultánea. Quaderns. Revista de traducción 2, 1(1), 107-117.

[13] Lopera, F. (2008). Funciones Ejecutivas: Aspectos Clínicos. Revista Neuropsicología, Neuropsiquiatría y Neurociencias, 8(1), 59-76.

[14] Orrego, M. \& Tamayo, O. (2016). Bases moleculares de la memoria y su relación con el aprendizaje. Archivos de Medicina, 16(2), 467-484.

[15] Tirapu, J. \& Muñoz, J.M. (2005). Memoria y funciones ejecutivas. Revista de Neurología, 41(8), 475-484. Recuperado de: https://www.uma.es/media/files/Memoria_y_funciones_ejecutivas.pdf

[16] Manes, F. \& Torralba, T. (2005). Funciones ejecutivas y trastornos del lóbulo frontal. Revista de Psicología, 1(2), 31-52. Recuperado de: https://repositorio.uca.edu.ar/bitstream/123456789/6236/1/funcionesejecutivas-trastornos-lobulo-frontal.pdf

[17] Baddeley, A. (2012). Working Memory: Theories, Models, and Controversies. Annual Review of Psychology, 63(1), 1-29. https://doi.org/10.1146/annurev-psych-120710-100422.

[18] Etchepareborda, M.C. y Abad, L. (2005). Memoria de trabajo en los procesos básicos del apendizaje. Revista de neurología, 40(1), 79-83.

[19] Aguilar, S. G., Gutiérrez, L. y Samudio, M.A. (2018). Estimulación de la atención y la memoria en adultos mayores con deterioro cognitivo. México: Permanyer.

[20] Cárdenas, D. C., Rojas, A. F., Cuellar, S. T. y Castañeda, N. N. (2017). Estrategias de estimulación cognitiva para la mejora de la atención en adultos con diagnóstico de discapacidad intelectual. Revista Psicoespacios, 11(19), 1-21. Recuperado de: https://revistas.iue.edu.co/index.php/Psicoespacios/article/view/949/13 46

[21] González, S., Fernández, F.H. y Duarte, J.E. (2016). Memoria de trabajo y aprendizaje: Implicaciones para la educación. Saber, ciencia y libertad, 11(2), 147-162. Recuperado de: https://dialnet.unirioja.es/servlet/articulo?codigo $=5880876$ 
Publicación semestral, Boletín Científico de la Escuela Superior Atotonilco de Tula, Vol. 9, No. 17 (2022) 45-52

[22] Herdt, R.B. y Pohl, B.N. (2018). Efectos del programa de estimulación de la memoria de trabajo en la madurez neuropsicológica en niños de la sala 5 (Tesis de Licenciatura). Pontificia Universidad Católica Argentina, Facultad "Teresa de Ávila”.

[23] Papalia, D.E., Wendkos, S. y Duskin, R. (2009). Psicología del desarrollo. (11 ${ }^{a}$ Ed.). México: Mcgraw Hill. 